$\sqrt{3}$

J. bio-sci. 17: 113-116, 2009.

ISSN 1023-8654

http://www.banglajol.info/index.php/JBS/index

\title{
RACIAL VARIATION IN SERUM LIPID AND LIPOPROTEIN LEVELS IN TYPE 2 DIABETIC SUBJECTS OF BANGLADESH
}

\author{
Mohammad Razuanul Hoque*, Md Golam Kabir, Dwaipayan Sikdar \\ Department of Biochemistry and Molecular Biology, University of Chittagong, Chittagong-4331, Bangladesh
}

\begin{abstract}
Context: Racial and sex differences are documented globally regarding patterns of serum lipids among diabetic patients. Differences of lipid profile of normal and diabetic subjects of the different ethnic groups of Bangladesh may differ.
\end{abstract}

Objectives: To find out if there were any differences in the serum lipid and lipoprotein levels in the type 2 diabetic patients of two different races namely, Bangalee and Chakma of Bangladesh.

Materials and Methods: Study population consisted of 76 (Chakma / Bangalee: 35 / 41) patients aged between 40-60 years with type 2 diabetes mellitus who were on follow-up at the Rangamati Diabetes Hospital, Chittagong Hill Tract, Bangladesh and forty (Chakma / Bangalee: 20 / 20) non-diabetic subjects of same age were randomly selected as control. Biochemical parameters analyzed include Serum total cholesterol and triglyceride (TG), serum high-density lipoprotein (HDL), low-density lipoprotein (LDL) cholesterol and atherogenic index.

Results: Dyslipidemia was found in the diabetic patients of both races and the patients had higher serum TG), atherogenic index and lower serum HDL than their normal counterpart. The Bangalee patients were found to have higher TG and lower atherogenic index compared with the Chakma patients although no racial differences found regarding total, HDL and LDL cholesterol. Also no differences were found between the lipid profiles of normal control subjects of these two races.

Conclusion: Present study confirms that racial differences exist in serum lipid abnormalities between Chakma and Bangalee subjects with type 2 diabetes.

Key words: Diabetes Type 2, Triglyceride, Lipoprotein, Total cholesterol, Bangalee, Chakma.

\section{Introduction}

Diabetes is associated with a greater risk of morbidity and mortality from cardiovascular disease and heart disease is the leading cause of death among people with diabetes (ADA 1996). Individuals with diabetes mellitus, especially those with type 2 diabetes, are frequently hyperlipidemic and are at increased risk for coronary heart disease (CHD) (Pyrola et al. 1987). Patients with this disease have been found to have less favorable lipid profiles than non-diabetes, which may explain part of their accelerated atherosclerosis process.

Race and sex differences in patterns of serum lipids have been noted in diabetes. African-Americans with type 2 diabetes reportedly have lower serum triglyceride (TG) and higher high-density lipoprotein (HDL) cholesterol concentrations than Caucasians and woman with diabetes have higher low-density lipoprotein (LDL) and HDL cholesterol concentrations than their male counterparts (Cowie et al.1994, Werk et al. 1993, Summerson et al. 1992). In non-diabetic individuals, there is also evidence of racial differences in lipid and lipoprotein levels, as black subjects have been found to have lower levels of HDL cholesterol (Tyroler et al. 1975, 1980, Frerichs et al. 1976, Srinivasan et al. 1976, Slack et al. 1977, Morrison et al. 1979ab, 1981, Glueck et al. 1984). Black subjects have also been found to have higher levels of lipoprotein (Guyton et al. 1985).

" Corresponding author 
In Bangladesh, people of different races e.g. Bangalee, Chakma, Marma, Tripura etc. are living. No study has been conducted to examine if there are any differences in lipid and lipoprotein levels in the diabetic subjects of these different races. The aim of this investigation was to determine variation in the lipid and lipoprotein levels in two races, Bangalee (Proto-Austriod or Veddas in origin and the mainstream population) and Chakma (Tibeto-Mongoloids in origin and tribal population) of Bangladesh in patients with type 2 diabetes.

\section{Materials and Methods}

Study population consisted of 76 (Chakma/Bangalee: 35/41) patients aged between 40-60 years with type 2 diabetes mellitus. The patients were on follow-up at the Rangamati Diabetes Hospital, Rangamati, Chittagong Hill Tracts, Bangladesh. Patients for type 2 diabetes were recruited on a consecutive basis, between March to April 2005, as they attended the hospital for follow-up. Only those type 2 diabetic subjects who have not taken any lipid lowering drugs including insulin, antihypertensives were included in this study. Patients not belonging to any of the two major ethnic groups consisting of Chakma and Bangalee were excluded. Forty (Chakma/Bangalee: 20/20) non-diabetic subjects of same age were randomly selected for control.

After a $12 \mathrm{~h}$ fast, venous blood of each patient and control subject was drawn for determination of lipid levels. Serum total cholesterol and triglyceride were measured by enzymatic colorimetric (GPO-PAP) method (Biedel et al.1983) and serum HDL was measured by enzymatic colorimetric (Cholesterol CHOD-PAP) method (Lopes-Virella and Stone 1977) using RA -50 Chemistry Analyser using reagents of Randox Laboratories Ltd., UK. (Bucolo and David 1983). LDL-Cholesterol was calculated from the estimated serum triglycerides, Total Cholesterol (TC) and HDL-Cholesterol by using the Friedwald's formula (Friedewald et al.1972). Atherogenic index was calculated from the estimated serum total cholesterol and serum HDL-C. It is simply done by dividing serum total cholesterol value by serum HDL-C value.

\section{Results}

Serum lipid and lipoprotein concentrations in type 2 diabetic Chakma subjects, type 2 diabetic Bangalee subjects, normal Chakma subjects and normal Bangalee subjects are presented in the Table I. When the lipid profiles of type 2 diabetic Chakma subjects were compared with the normal Chakma subjects, an increase in TC, TG, LDL and TC/HDL values were found in the former group. Again there was decrease in $\mathrm{HDL}$ value in the former group. Increase in TG and TC: HDL values were found to be highly significant $(p<0.01)$ whereas decrease in HDL values were highly significant $(p<0.01)$, while increase in TC and LDL value was insignificant. When the lipid profile of type 2 diabetic Bangalee subjects were compared with that of normal Bangalee subjects, TC, TG, LDL and TC: HDL values were found to be higher and HDL value was lower in the former group. In this comparison, increase in TG and TC/HDL values was highly significant $(p<0.01)$, while decrease in HDL was also highly significant $(p<0.01)$. No significant increase was found in TC and LDL values.

When the lipid profile of type 2 diabetic Chakma patients were compared with that of type 2 diabetic Bangalee patients, the values of TC, TG, LDL and TC: HDL were found to be lower and HDL was found to be higher in the former group. Among these parameters, the difference was highly significant for TG $(p<0.01)$, significant for atherogenic index $(p<0.05)$ and insignificant for TC, LDL-C and HDL-C.

When the lipid profiles of normal Chakma subjects were compared with the normal Bangalee subjects, a higher TC, TG and LDL-C values were found in the former. On the other hand, HDL and TC/HDL were almost identical between these two different ethnic groups. The decrease in TC, TG and LDL-C were not significant at all. So, there is no significant difference in the lipid profile of normal control subjects from these two diverse races. 
Table 1. Serum lipid and lipoprotein comparison among type 2 diabetic Chakma, Bangalee and their control populations.

\begin{tabular}{|c|c|c|c|c|c|c|c|}
\hline \multirow[b]{2}{*}{$\begin{array}{c}\text { Variables } \\
(\mathrm{mg} / \mathrm{dl})\end{array}$} & \multicolumn{2}{|c|}{ Chakma } & \multicolumn{2}{|c|}{ Bangalee } & \multicolumn{3}{|c|}{$P$ value } \\
\hline & $\begin{array}{c}\text { Diabetic (DC) } \\
n=35\end{array}$ & $\begin{array}{c}\text { Control (CC) } \\
n=20\end{array}$ & $\begin{array}{c}\text { Diabetic (DB) } \\
n=41\end{array}$ & $\begin{array}{c}\text { Controln (CB) } \\
n=20\end{array}$ & $\begin{array}{l}C B \\
\text { vs } \\
D B\end{array}$ & $\begin{array}{l}C C \\
\text { vs } \\
D C\end{array}$ & $\begin{array}{l}\mathrm{DB} \\
\text { vs } \\
\mathrm{DC}\end{array}$ \\
\hline$\overline{\mathrm{TC}}$ & $185.83 \pm 26.65$ & $177.2 \pm 26.97$ & $193.24 \pm 9.43$ & $190.30 \pm 12.08$ & $\mathrm{~ns}$ & ns & ns \\
\hline TG & $164.20 \pm 30.64$ & $133.6 \pm 32.89$ & $192.24 \pm 35.83$ & $148.30 \pm 8.43$ & $<0.01$ & $<0.01$ & $<0.01$ \\
\hline HDL & $33.74 \pm 4.35$ & $40.10 \pm 6.12$ & $32.41 \pm 5.13$ & $40.80 \pm 6.75$ & $<0.01$ & $<0.01$ & $\mathrm{~ns}$ \\
\hline LDL & $119.00 \pm 23.49$ & $112.60 \pm 19.86$ & $122.17 \pm 8.76$ & $118.30 \pm 3.21$ & ns & ns & ns \\
\hline TC:HDL & $5.56 \pm 0.91$ & $4.49 \pm 0.84$ & $6.07 \pm 0.75$ & $4.80 \pm 0.92$ & $<0.01$ & $<0.01$ & $<0.05$ \\
\hline
\end{tabular}

\section{Discussion}

The present results confirm that racial differences exist in serum lipid abnormalities between Chakma and Bangalee subjects with type 2 diabetes. The Chakma patients had lower TG value $(p<0.01)$ and higher atherogenic index $(p<0.05)$ compared with Bangalee patients. Although the control subjects of both races didn't show any differences in their serum lipid and lipoproteins level, diabetes induced elevation of TG was higher in Bangalee patients compared to the Chakma patients. So it is vivid from this study that Chakma type 2 diabetic patients were found to have an improved lipid and lipoprotein profile compared with their Bangalee counterparts. As the atherogenic index is proposed to be the best indicator of cardiovascular risk (Kannel et al.1979), higher HDL-cholesterol levels and an improved atherogenic index among Chakmas than Bangalees suggest that they may have lower CHD incidence. However, studies on racial differences concerning lipid levels in type 2 diabetic subjects are few.

Earlier Pacy et al. (1987) demonstrated that ethnic difference was noted for each variety of hyperlipidemia, being most marked for hypertriglyceridemia in type 2 diabetic subjects and blacks had lower mean triglyceride levels than whites $(p<0.01)$ and Asians $(p<0.01)$. In addition, blacks had higher HDL-cholesterol than whites $(p<0.01)$ and Asians $(p<0.01)$ and HDL2-cholesterol was higher in blacks than Asians $(p<0.01)$. Later Summerson et al. (1992) also found low level of triglyceride and high level of HDL-cholesterol and improved atherogenic index in black type 2 diabetic patient compared with the white type 2 diabetic patient. Cowie et al. (1994) further found that lipid profiles appeared to be worse in whites with type 2 diabetes than in African Americans.

\section{Conclusion}

Our results help to establish that racial differences exist regarding serum lipid and lipoprotein levels in patients with Type 2 diabetes. Although we did not extensively examine the mechanisms behind the racial differences in the lipid profile of type 2 diabetic subjects, we speculate that they may be related to the differential metabolism of lipids. Because of the consistent differences found in the Chakmas and Bangalees, it appears that a genetic hypothesis is plausible. Further studies of genetic factors related to elevated lipid levels may help to clarify their role in the atherosclerotic process.

\section{Acknowledgement}

This study was supported in part by a grant from Research Cell, University of Chittagong, Bangladesh. The authors are thankful to Professor Soma Chowdhury, Department of Statistics, of the same university for her kind help in statistical analysis of the data. 


\section{References}

ADA (American Diabetes Association) 1996. Diabetes Vital Statistics. Alexandria, VA. American Diabetic Association.

Biedel J, Hagel ED, Zigenhorn J. 1983. Reagent for the enzymatic determination of serum total cholesterol with improved lipolytic efficiency. Clin Chem, 29, 1075-1060.

Bucolo G, David H. 1983. Quantitative determination of serum triglycerides by the use of enzymes. Clin Chem, 29, 476-482.

Cowie CC, Howard BV, Harris MI. 1994. Serum lipoproteins in African Americans and whites with non-insulin- dependent diabetes in the US population. Circulation, 90, 1185-1193.

Frerichs RR, Srinivasan SR, Webber LS. 1976. Serum cholesterol and triglyceride levels in 3446 children from a biracial community: The Bogalusa heart study. Circulation, 54, 302-308.

Friedewald WT, Levy RI, Fredrickson DS. 1972. Estimation of the concentration of low density lipoprotein cholesterol in plasm without use of the preparative ultracentrifuge. Clin Chem, 18, 499-502.

Glueck CJ, Gartside P, Laskarzewski PM. 1984. High density lipoprotein cholesterol in blacks and whites: Potential ramifications for coronary heart disease. Am Heart J, 108, 815-826. doi:10.1016/0002-8703(84)90677-X

Guyton JR, Dahlen GH, Patsch W. 1985. Relationship of plasma lipoprotein (a) to race and apolipoproteins (b). Atherosclerosis, 5, 265-272.

Kannel WB, Castelli WP, Gordon T. 1979. Cholesterol in the prediction of atherosclerotic disease. Ann Intern Med 90, 85-91.

Lopes-Virella MF, Stone P. 1977. Cholesterol determination in high density lipoproteins separated by three different methods. Clin Chem, 23, 882-884.

Morrison JA, DeGroot I, Kelly KA. 1979. Black-white differences in plasma lipids and lipoproteins in adults: The Cincinnati Lipid Research Clinic Population Study. Prev Med. 8, 34-39. doi:10.1016/0091-7435(79)90027-6

Morrison JA, DeGroot I, Kelly KA. 1979. Black-white differences in plasma lipoproteins in Cincinnati school children. Metabolism, 28, 241-245. doi:10.1016/0026-0495(79)90070-2

Morrison JA, Khoury P, Mellies M. 1981. Lipid and Lipoprotein distributions in black adults: The Cincinnati Lipid Research Clinics Princeton School Study. JAMA, 245, 939-942.

Pyrola K, Laakso M, Uusitupa M. 1987. Diabetes and arteriosclerosis: An epidemiological view. Diabetes Metab Rev, 3, 463-524. doi:10.1002/dmr.5610030206

Slack J, Noble N, Meade TW. 1977. Lipid and lipoprotein concentrations in 1604 men and women in working populations in northwest London. Br. Med J, 2, 353-356.

Srinivasan SR, Frerichs RR and Webber LS. 1976. Serum lipoprotein profile in children from a biracial community. The Bogalusa Heart Study. Circulation, 54, 309-318.

Summerson JH, Konen JC, Dignan MB. 1992. Racial differences in lipid and lipoprotein levels in diabetes. Metabolism; 41( 8), 851-855. doi:10.1016/0026-0495(92)90166-8

Tyroler HA, Hames CG, Krishan A. 1975. Black-white differences in serum lipids and lipoproteins in Evans County. Prev Med, 4, 541-549. doi:10.1016/0091-7435(75)90040-7

Tyroler HA Glueck CJ, Christensen B. 1980. Plasma high-density lipoprotein cholesterol comparison in black and white population: The Lipid Research Clinics Program. Prevalence Study. Circulation, 62, 99-107 (Suppl 4).

Werk EE Jr, Gonjalez JJ, Ranney JE. 1993. Lipid level differences and hypertension effect in blacks and whites with type II diabetes. Ethn. Dis, 3, 242-249. 